\title{
An Experimental Study on Prototyping Algorithm Implementation
}

\author{
Prof. Madhuri Zambre \\ Professor, Department of Electrical Engineering, \\ Modern College of Engineering Pune India \\ madhurizambre01@gmail.com
}

\author{
Article Info \\ Page Number: 99 - 101 \\ Publication Issue: \\ Vol 71 No. 1 (2022)
}

\section{Article History}

Article Received: 18 November 2021

Revised: 03 December 2021

Accepted: 19 December 2021

Publication: 28 January 2022

\begin{abstract}
We created a rough prototype of the device on paper, in order to create the product rapidly and efficiently. Further, we researched about various sensors and microcontrollers to make it as affordable as possible. Understanding the working for a passive infrared sensor was a major part of building the circuit. The PIR sensor had a 3-pin connection at the side, one pin was the ground, another signal and the last one was power. we powered the PIR with the help of $5 \mathrm{~V}$ battery and connect ground to ground; then connected the output to a digital pin. After attaching the PIR and testing it with the help of an LED, we attached the ISD1820, to play the required sound.
\end{abstract}

Keywords: - Prototyping Algorithm, PIR etc.

\section{Introduction}

Over the years, farmers in many regions of India have been tackling the issue of crop loss due to wild animals through preventive measures such as using red chili smoke or playing loud percussion, and ameliorative measures such as requesting the Govt for insurance and compensation. My research confirmed the severity of the situation and the urgency of the problem: Agriculture supports $50 \%$ of India's population and only $18 \%$ of the GDP, and losing income due to wild animals leaves farmers in despair for the season $[1,2]$. According to the survey conducted by the NABARD, the average size of an Indian farm is 1.2 Hectares which is $11600 \mathrm{~m}^{2)}$, and therefore has an average side of approximately $107 \mathrm{~m}$. Existing technology such as electric fencing costs Rs. 200/meter and thus the average cost per farm will be Rs. 85,600 [3]. However, the average income of a farmer is only Rs 77,976 per year according to the Economic Survey conducted by Dalai committee - and hence electric is clearly an unaffordable solution for the average farmer. Hence my aim is to create a product which they can actually afford [4]. The main challenge was to accurately follow the circuit diagram and put together all the components. After extensive research and with the help of my teachers, we was able to assemble the electrical and mechanical components. At the same time, it also gave me the opportunity to increase my understanding and knowledge of electric currents, Arduino programs, conversion of voltages etc [5]. The research we conducted ensured me that my product was not only feasible but also easy to replicate on a mass scale. 


\section{Methodology}

Arduino code had five parts: a header, two sections stating variables, lists and comments; a setup routine; a loop routine, for the main code body which is responsible for implementing the code. After writing the code, we uploaded it, and then disconnected it from the computer and combined it with my project.

I joined various other components later, to improve the device. First we attached a rechargeable battery as it is easier to use and implement in rural areas. At the same time it is also cost effective and environment friendly. While testing the product, the noise was quite distorted. Therefore, we decided to attach an amplifier to boast the signals. we also attached a loud speaker to ensure, that the sound is audible. Finally, we also connect a solar panel in the circuit because it is a renewable source of electricity, cost effective and requires less maintenance.

\section{Results and Discussion}

PIR sensor and Arduino Programmer: The sensor worked well, and detected motion with 10m of its range. However the PCU board was quite fragile to handle so we decided to attach it to a cardboard piece. Using the Arduino Programmer and tested different codes, we finalised on the one which provided high sensitivity. The circuit required to be small and compact, and PIR sensors proved to be the perfect fit. Arduino is an open source platform which was quite helpful, developing and testing the device became easier. Programming the micro-controllers and software wasn't time consuming once we understood the syntax.

Cost: According to the survey conducted by the National Bank for Agricultural and Rural Development, the average size of an Indian farm is 1.2 Hectares $(11600 \mathrm{~m} 2)$ i.e. one side will be approximately $107 \mathrm{~m}$. The range of a passive infrared sensor is $10 \mathrm{~m}$, hence every $20 \mathrm{~m}$ will require $1 \mathrm{PIR}$. Therefore on an average, a farm will require 24 motion sensors. Total Cost would be Rs 3,750. Therefore, the product is extremely cost-effective, and can also be produced at a mass scale easily. The overall goal of the project was to build sustainable solution for Indian farmers. we gained a lot of knowledge about various aspects of engineering be it electrical, mechanical or technical. The whole project resulted in me gaining more curiosity about the world or science and its applications. Here, a protective cover must be created to ensure that the circuit doesn't get damaged in case of extreme weathers. The electricity bill, in case of absence sunlight, wasn't taken into account. This device aims to facilitate peaceful co-existence between the ecosystem and the human's ever-increasing needs, we hope the device can inspire a discussion and action around ecologically sustainable ways of exploiting our resources. Science and technology have always bought solutions to our toughest challenges and my modest effort is to suggest that this quest can continue on what are seemingly intractable problems today.

\section{Conclusion}

We would like to further research on how weight sensors can be manipulated. This device has not only verified my hypothesis but also open new horizons for research. we would further like to study and track the movement of animals around the fields, to further customize the product. Understanding the need for wild animals, and what forces them to leave their natural habitats, disturbance to the ecosystem would be my next goal. After understanding the power that science and technologically hold, it has motivated me even more to follow my passion and build more. we have succeeded in developing the device which we proposed to and have also met my hypothesis by successfully creating a low cost, solar 
powered device which uses acoustical behavior of animals to manipulate their movement. The device is the most affordable alternative for Indian farmers and can hugely benefit them.

The device can adapt by every region of India. As soon as my device senses thermal energy i.e. motion, the passive infrared sensor sends a signal to voice modular through the coded Arduino to play the required sound. To make the device inexpensive and easy to replicate we have used Arduino as the microcontroller, and also incorporated passive infrared sensors to detect thermal energy even though it is quite complex and has two slots to detect motion it smaller in size, affordable and doesn't get corroded easily. While creating my device, we learnt that solving a real-life issue requires merging all sphere of sciences to produce an equipment that can aid the one's in need.

\section{References}

[1] Ahmadi, M.H., Ghazvini, M. \& Sadeghzadeh, M. et al. 2018, Solar power technology for electricity generation: A critical review. Energy Science \& Engineering, 6, 340-361

[2] Ali, A.H. 2018, Experimental Study on Performance of Solar Thermal Driven Cooling System versus a Hybrid Mechanical Compression Refrigeration-Solar Thermal Assisted System in Hot Areas. Faculty of Engineering, Assiut University

[3] Australian Government Department of Resources, Energy and Tourism 2010, Australia Energy Resource Assessment ( $2^{\text {nd }}$ Ed.). commonwealth of Australia

[4] Eryılmaz, M., Önder . Ertan, F. . Yalçınkaya, and E. . Kara. "A Prediction Study about the Pandemic Era Based on Machine Learning Methods". International Journal on Recent and Innovation Trends in Computing and Communication, vol. 9, no. 12, Dec. 2021, pp. 01-07, doi:10.17762/ijritcc.v9i12.5492.

[5] Moss, J., Coram, A. \& Blashki, G. 2014, Solar Energy in Australia: Health and Environmental Costs and Benefits. The Australia Institute

[6] Teske, S., Crespo, L. \& Richter, C. 2016, Solar Thermal Energy: Global Outlook 2016. The European Solar Thermal Electricity Association (ESTELA), Greenpeace International and SolarPACES.

[7] Singh, S. ., Wable, S. ., \& Kharose, P. . (2022). A Review Of E-Voting System Based on Blockchain Technology. International Journal of New Practices in Management and Engineering, 10(04), 09-13. https://doi.org/10.17762/ijnpme.v10i04.125 